\title{
Long and Short-Run Relationship Between Agricultural and Industrial Sectors' Growth in Ethiopian Economy: Application of the Co-Integration and Error Correction Model (ECM)
}

\author{
Fisseha Seyoum \\ Haramaya University, College of Agricultural and Environment Sciences, \\ Department Agricultural Economics and Agribusiness, P. O. Box 138; Dire Dawa, Ethiopia
}

\begin{abstract}
The objective of this paper was to examine an equilibrium long run relationship and short impact of agricultural sector on the industrial sector and to determine the direction of causality in Ethiopia's economy using annual time series data ranging from 1991-2015 obtained from the World Development Indicators (WDI) database. The time was related to the implementation of the Ethiopian agricultural led industrialization (ADLI) strategy policy to food security and poverty reduction objectives of the country. The Johansen Co-integration test result showed that the data were co-integrated of the ordered one. The Johansen's co-integration tests, both trace and max-trace statistical tests was significant at $1 \%$ critical values indicated that there was a strong long-run equilibrium relationship between agricultural and industrial sectors. The Johansen restricted normalized equations error correction model $(E C M)$ indicated that agricultural has long run positive significant impact on industrial sector but not vice versa. Marginal analysis result indicated that increases agricultural by one percent, being other factors held constant, the industrial sector output increase by $3.39 \%$ due to economic multiplier effect. Granger pairwise causality test revealed that there exists unidirectional causality from industry to agriculture sector. In the long-run growth come from agriculture to industry and in the short run agricultural growth is caused by industry. Therefore, ADLI economic growth strategy should strengthened the sectors forward and backward linkages to bring balance and rapid sectorial growth that support the entire economic growth of the country.
\end{abstract}

Keywords:ADLI, Co-Integration, Ethiopia, Industry, Integration, VECM.

DOI: $10.7176 / \mathrm{JESD} / 12-1-02$

Publication date: January $31^{\text {st }} 2021$

\section{INTRODUCTION}

In Ethiopia, agriculture is the most important and considered a leading sector for its economic growth. The report by Ministry of Finance and Economic Development (MoFED, 2014), showed that Ethiopia's agriculture is the source employment for more than $85 \%$ of its population as their livelihood, $40 \%$ national GDP, $90 \%$ exports and provides basic needs to more than $90 \%$ of the rural poor.

In Ethiopia's economic history, agriculture is the most dominant sector to bring economic growth, food security, poverty reduction, and foreign earnings. However, the sector's inherited immediate smallholder, subsistent that depend on traditional, fragile institutional support contribute to low productivity, food insecurity, poverty, and low capital formation to support the industrial sector development in the country and could not able to realize the long-standing national economic growth and development objectives.

According to the Ethiopian ADLI growth document 2007, the Ethiopia economic growth and development genesis is agriculture and agricultural lead indoctrination (ADLI) strategy assumes that economic growth starts from agriculture and motivates the growth of other sectors particularly the industrial sector. This ADLI growth theory was formulated under the experience of the East Asian developing countries agricultural-industrial growth model. In the Ethiopian economy, the most important and paradox is how smallholder less than 0.5 per households, subsistence, low and declining in productivity per capita agriculture that cannot able to feed its people can provide raw material to the industry and form capital to develop industry?. To solve productivity constraints and the paradox, the Ethiopian government has been taking different activities including promotion of the supply of input and productivity-enhancing technological packages through specialized extension agents.

Since the adoption of the Ethiopian ADLI strategy, the country economy has shown significant improvement registering a growth economic for a decade and the strategy is considered as the promising to bring rapid, broadbased economic growth that improved absolute poverty of the country from more than $50 \%$ to $30 \%$. However, because of environmental degradation, the use of traditional technology, food insecurity; the Ethiopian agriculture sector, and the Ethiopian ADLI growth strategy's sustainability that lead to industrial development and many challenges.

According to Alston and Pardey (2014), 95\% Ethiopian agriculture is vulnerable to climate change and drought, highly fragmented land degrdation on average less than 0.2 hectare per household in high land area. In Ethiopia $90 \%$ of smallholder, farmers are subsistence farmers produce hand to mouth for their consumption that cannot produce a surplus for market or industry, so it can't lay a foundation for industrial growth conditions 
including capital formation. This shows that there are different views on Ethiopian agricultural led industrialization strategy.

Historically, although the effort of industrializing in the Ethiopian economy was initiated in the 1950s that was focused on generous tax incentives, a high level of tariff protection and the provision of credit by Ethiopia banks on favorable terms encourage an inflow of foreign capital into the industrial sector considered as strategies. However, since most of these foreign-owned enterprises depended on import raw materials and had a lack of forwarding and backward linkage with the local economy the effort was not succeeded (UNIDO, 2000).

During the 1970s, the Derg-regime also initiated large-scale, modern, and capital intensive industrial production project-based strategies that had worsened the industry's dependence on imported technology and handicapped the development of a domestic manufacturing capability of the country. New large-scale capitalintensive projects that had been taken higher investment funds allocated to the industry sector. Such projects were costly in terms of foreign exchange, both in the short-term, as virtually all the machinery has to be imported and over the long-term owing to continued imports of spare-parts and intermediate goods and debt servicing obligation. Despite industrial orientation towards the domestic market, it draws heavily on imports for inputs. This also had a backward and forward linkage between agriculture and industry. Both industry and agriculture in Ethiopia were assumed at the infant stage when ADLI 1991 strategy was designed and hoped to solve forward and backward linkage between the strategies of the sector to transform the economy of the country.

There was a strong debate on the Ethiopian ADLI strategy. The government explains that the ADLI strategy is the right policy strategy since it has showed registered double-digit economic growth in the country. On the other side, the policy opponents doubt ADLI sustainability to bring economic growth, poverty reduction, and food security national objectives. There is a scarcity of information related to the long-run relationship or impact between agricultural and industrial sectors; the direction of causalities between the sectors in the economy. Therefore, the major objective of this study was to assess the contribution of the growth of the agricultural sector to the growth of the industrial sector in Ethiopia. Specifically, the study is set out to examine if there exists a significant long-run impact of agricultural output on the growth of industrial sector output and the direction of short-run causality between the agricultural sector and industrial sectors in Ethiopia.

\section{Methodology}

This section deals with the methodological issues and empirical results of the study to accomplish the objectives of the study that determine the short-run and long-run relationship between agriculture and industry sectors and the direction of the causality in Ethiopia.

\subsection{Sources of data}

This study used annual based time series data of agriculture and industry annual total sector contribution series from 1999 to 2015 to Ethiopia economy. The period was selected based on the adoption of the Ethiopia ADLI. Annual time series data of agriculture and economic growth for the period of 1982-2015 data collected from World Development Indicators (WDI) of the World Bank data. As this study examines the short run and long run agriculture and industry sectors relationship, secondary data is appropriate for the study.

\subsection{Variables definitions}

Ethiopian agriculture includes cultivation of crops and livestock production as well as forestry and fishing. Agricultural output is defined as the annual agricultural value output of the sector converted into local currency after adding up all outputs and subtracting intermediate inputs. The Ethiopian industrial sector also comprises value added in agro-processing, mining, manufacturing, construction, electricity, and water. The sector annual output valued was the net output of the sector after adding up all outputs and subtracting intermediate inputs. Both the agricultural and industrial sectors were calculated without making deductions for depreciation of fabricated assets or depletion and degradation of natural resources.

\subsection{Analytical Techniques}

Theoretical, a number of variables that influences industrial development is identified and analyzed with the long and short run, and direction of impact. It was shown that industrial development is a function of agricultural output (agri), exchange rate (exe), and other factors affecting industry output. Thus, the model for this study is specified in line with the above analysis as shown below:

indu $=$ (Aagri, other variables)

Given the fact that independent variables such as agriculture, exchange, interest rate, and foreign direct investment determine the changes in the dependent variable industrial output, the functional relationship between the dependent and explanatory variables in the linear equation is specified as shown below:

$\operatorname{login}=\mathrm{b} 0_{\mathrm{t}}+\mathrm{b} 1$ agrit $_{\mathrm{t}}+\varepsilon \mathrm{t}$

Following the Reynold (1985) and Ajayi (1978), the data of the variables in equation (2) is transformed into 
logarithm to remove lags. This is because using the raw data as they may lead to bias resulting in violation of the ordinary least squares and vector error correction model (VECM) assumptions. As a result, the log specification becomes:

Logagrit $=b 0_{t}+b 1 \operatorname{Logind~}_{t}+\varepsilon_{t}$

Where:

Log indu $=$ logarithm of industrial output

Log agri $=$ logagrit of agricultural output

$\varepsilon_{\mathrm{t}}=$ stochastic error term

$\mathrm{b}_{0}, \mathrm{~b}_{1}=$ represent the coefficients to determine the direction of the relationship between agriculture and industry in Ethiopia, the study was focused only on the relationship between agriculture and industry sectors.

\subsection{Estimation Technique}

\subsubsection{Stationarity Test}

The first step taken to estimate the specified model is to determine the stationarity of the data used to assure the variables have stable mean and variance so that the resultant regression results are meaningful. Otherwise, if nonstationarity of the variable is present and not checked, the existence of drift in the data sequence will signify that the regression outcome was spurious. There are three different methods for the determination of unit root, namely Augmented Dickey-Fuller (ADF) (1979), Phillips-Perron (PP) (1988), and Kwiatkowski, Phillips, Schmidt, and Shin (KPSS) (1992) unit root tests. Each method has three models to be used such as intercept only, intercept and slope, and no intercept and slope models. In this paper, ADF unit root techniques were used to check whether or not the variables used in the analysis are stationary or not which in turn determine the model selection of the analysis.

Augmented Dickey-Fuller (ADF) Test Dickey (1976), and Dickey and Fuller (1979, 1981) developed a method for testing the stationarity of a time series variable by directly testing the null hypothesis of the unit root (non-stationarity). The original Dickey-Fuller (DF) test is based on a simple Autoregressive of order one, the AR (1) process with a white-noise disturbance. However, because of the DF test regression does not include values of variables beyond one lag, the error terms may be serially correlated; results based on such tests may be biased and are not valid (Gujarati, 2004). The ADF test avoids the autocorrelation problem because it corrects for serial correlation by adding lagged-difference terms (Greene, 2006). The followings the three ADF unit root models for indu variable:

$$
\begin{gathered}
\Delta i n d u=(\mathrm{P}-1) i n d u_{t-1}+\sum_{J=1}^{k} \theta_{j} \Delta i n d u_{t-1}+\varepsilon \\
\Delta i n d u=(\mathrm{P}-1) i n d u_{t-1}+\sum_{J=1}^{k} \theta_{j} \Delta i n d u_{t-1}+\alpha+\varepsilon \\
\Delta i n d u=(\mathrm{P}-1) i n d u_{t-1}+\sum_{J=1}^{k} \theta_{j} \Delta i n d u_{t-1}+\alpha+\beta_{t}+\varepsilon
\end{gathered}
$$

where $\Delta$ is the difference operator, $k$ is the auto-regressive lag length, $J$ is the number of observations in the sample, $\varepsilon$ is assumed to be a Gaussian white noise random error in the three forms, $t=1, \ldots, T$ is a term for trend and $\mathrm{P}$, $\alpha$ and $\beta$ are the coefficients of interest. Equation (1) represents model 1 (no constant, no trend), equation (2) model 2 (constant, no trend) and equation (3) model 3 (constant, trend).

\subsubsection{Johansen Co-Integration Test}

Before moving to a co-integration test, firstly there need to determine the optimal lag-length using the most known information criteria including Akaki Information Criteria (AIC), Bayesian information criteria (BIC), and Schewerize Information Criteria (SIC). When the two or more series variables under consideration are nonstationary at a level and confirmed indifference unit root test to have the same ordered of stationarity, an order of " $\mathrm{d}$ " integration, the second step required is testing for co-integration among the series used. Co-integration refers to a long-run equilibrium link among the series variables. The stationarity process signals the existence of longrun relationships among data. This paper will employ Johansen $(1991,1995)$ co-integration procedure because this approach is performing better than other co-integration tests (Gonzalo 1994). In conducting the Johansen cointegration test, the following estimate the following model:

$$
\Delta y_{t}=\pi y_{t-1}+\sum_{t=1}^{p-1} \Gamma_{t} \Delta y_{t-1}+u
$$


Where $\pi=\sum_{t=1}^{p-1} A_{t}-I \quad \Gamma=-\sum_{j=i+1}^{P} A_{t}$

$\Delta$ is the first different operators, it is a vector of endogenous variables agriculture and industry and $v_{t}$ is the error term. The matrix $\Pi$ consists of long-run information between $y_{t}$ variables in the vector. We will examine the matrix rank, $r$, by testing the null hypothesis that the eigenvalues $\Pi$ is statistically different from zero. Two sets of statistics purposed by Johansen and Juselius (1990) which indicate the number of co-integrating rank, trace statistic, and maximum eigenvalue statistics;

$$
\begin{aligned}
& L R\left(\lambda_{\text {trace }}\right)=-T \sum_{i=r+1}^{k} \ln \left(1-\lambda_{i}\right) \\
& L R\left(\lambda_{\max }\right)=-T \ln \left(1-\lambda_{r+1)}\right)
\end{aligned}
$$

$\mathrm{T}$ is the number of observations, while $\lambda_{\mathrm{i}}$ is the estimated $p-r$ smallest eigenvalues. The null hypothesis for $\lambda$ max is $r$ of no cointegrating vectors against the alternative hypothesis that $r+1$ co-integrating vector.

\subsubsection{Vector Error Correction Model (VECM)}

There can be a long-run relationship between two series in a bivariate relationship if each series is integrated of the same order or have the same stochastic trend. If in this case, agriculture and industry are co-integrated, the first difference of agriculture and industry can be modeled using a VAR, augmented by including agriculture as additional regresses. VEC with two-time series variables is:

$$
\begin{aligned}
& \Delta \text { ind } u=\beta_{10}+\beta_{11} i n d u_{-1}+\ldots+\beta_{1 p} i n d u_{-p}+\alpha_{11} \Delta i n d u_{-1}+\ldots+\alpha_{1 p} \Delta a a g Q_{-p}+\delta_{1}\left(i n d u_{-1}-\pi a g t_{t-1}\right)+u_{1} \\
& \Delta a g r i=\beta_{20}+\beta_{21} \Delta i n d u_{t-1}+\ldots+\beta_{2 p} \Delta i n d \underline{u}_{-}+\alpha_{2} \Delta a g f_{-1}+\ldots+\alpha_{2 p} \Delta a g q_{-p}+\delta_{2}\left(i n d u_{-1}-\pi a g q_{-1}\right)+u_{2}
\end{aligned}
$$

Where $\Delta$ is difference operator, indu is lnindu, and agri is large, $\delta_{1}$ and $\delta 2$ are error correction coefficients, $\left(\right.$ ind $u_{t-1}-$ Magri $\left.t_{t-1}\right)$ the error correction term, $\mathrm{u}_{1}$, and $\mathrm{u}_{2}$ is the random term. In the VEC model, past values of the error correction term help to predict future values of describes how variables behave in the short run being consistent with the long run Co-integration relationship. A significant coefficient of the error correction term indicates any short term fluctuations between the independent variable and dependent variable will give rise to a stable long-run relationship. To identify the long-run relationship between agriculture and industry growth in Ethiopia, the model is applied.

\subsubsection{Granger-Causality Test}

The co-integration test between the two sectors series using Granger causation test at least in one direction Granger (1969). So at least one coefficient of the error term should enter to equations 13 or 14 significantly and bear the correct sign, i.e. negative.

$$
\begin{aligned}
& \Delta \text { indu }_{t}=\sum_{j=1}^{k} \alpha_{1 j} \Delta \operatorname{Iind} u_{t-j}+\sum_{j=1}^{k} \beta_{1 j} \Delta \text { agri }{ }_{t-j}+\varepsilon_{1 t} \\
& \Delta \text { agri }_{t}=\sum_{j=1}^{k} \alpha_{1 j} \Delta \text { indu }{ }_{t-j}+\sum_{j=1}^{k} \beta_{2 j} \Delta \text { Aagri }_{t-j}+\varepsilon_{2 t}
\end{aligned}
$$

Where $\Delta$ is the first difference operators indicate that the variables are in the short run process, while $\varepsilon_{1 t}$ and $\varepsilon_{2 t}$ are white noise residuals. $F$-test is used for a restriction on the VAR parameters. It is said that if there is exist a causality, the direction between agriculture and industrial sector, the coefficient $\alpha_{12}, \mathrm{k}$ should be different from zero, that is, by rejecting the null hypothesis, the null hypothesis is accepted that the agriculture sector has Grangercaused industrial sector. Similarly, if $\mathrm{H} 0: \alpha_{21} \mathrm{k}=0$; with no causality, it can be concluded that the industrial sector is the Granger-caused agriculture sector.

\subsubsection{Diagnostic Checks of the Variables}

\subsubsection{Autocorrelation test}

Autocorrelation refers to the existence of a relationship between error terms across observations of a time series. Error co-variances are therefore different from zero. This constitutes a violation of one of the assumptions of the classical linear model. Autocorrelation is manifested by OLS estimators which are not BLU (Best linear unbiased). In this study, an autocorrelation was tested using the Breusch-Godfrey (1978), serial correlation LM test. The decision rule is to accept the null hypothesis of no autocorrelation among the error term across the observation of time series if the probabilities of the F-statistics of the intermediary equation are greater than 0.05 , which depicts the absence of autocorrelation. On the other hand, the Alternative hypothesis of autocorrelation among the error term of the observation is not rejected if the probabilities of the F-statistic of the intermediary equation are lesser than 0.05 . 


\subsubsection{Residual vector normality test}

The test of normality of the residuals is one of the important post-estimation diagnostic tests in empirical studies. This study uses the multivariate extension of the Jarque-Bera $(J B)$ test for residual normality, which compares the third and fourth moments of the residuals to those from the normal distribution. This test is a joint asymptotic test in which the statistic is calculated from the skewness and kurtosis of the residuals as follows.

$$
J B=\frac{T}{6}\left[S^{2}+\frac{\left(\beta_{3-3}\right)}{4}\right]
$$

Where $\mathrm{T}$ is the number of observations, $\mathrm{S}$ is the coefficient of skewness, $\beta_{3}$ is a measure of kurtosis; and the test

statistic is $\chi^{2}$ distributed. The joint test is based on the null hypothesis that the residuals are normally distributed (i.e., $\mathrm{S}=0$ and $\beta_{3}=3$ ). Rejection of the null hypothesis at the standard critical values indicates the non-normality of the residuals.

\section{RESULT AND DISCUSSION}

\subsection{Descriptive Statistics}

Table 1 shows the summary of agriculture and industry series output. As can be seen, the mean of agriculture and industry is 14.1 billion and 3.18 billion Birr respectively over the time series period. It can also show that the standard deviation of agriculture is highly larger than the industry sector. This may be due to climatic variability affecting agricultural output performance.

Table 1. Descriptive Statistics of agricultural and industrial output (billion)

\begin{tabular}{llllll}
\hline Variable & Obs & Mean & Std. Dev. & Min & Max \\
\hline agri & 26 & 141 & 58.1 & 83.7 & 268 \\
indu & 26 & 3.18 & 24.7 & 9.73 & 105 \\
\hline
\end{tabular}

Source: Own Computation

\subsection{Econometric Analytical Test Results}

There are steps and procedures to test the short-run and long-run relationship between agriculture and industrial sector output series including, stationary and unit root test for integration and its order, co-integration if it exists and its number and short-run and long-run impact of the series. Post diagnostic test, which increases interpretation and reliability.

\subsection{Stationarity test}

The result of the ADF Unit Root test showed that the two variables were confirmed to be stationary only after their first differencing. The result conducted at both 1\% and 5\% levels of significance is presented in Table 2 below result shows that both the series namely; industrial output (indu) and agricultural output (agri) contained unit root at the level and are stationary only after first differencing, at 1\% and 5\% significant levels. This follows the decision rule, which states that when the computed ADF absolute value exceeds the absolute critical value, the null hypothesis is rejected and that the series is stationary and vice-versa. The stationaries of both the series in the same order were thus a motivation to run for co-integration tests to find out the presence or absence of any longrun relationship between the series. Because of the above, therefore, since the variables are stationary at the same order or I(1) orders, there was a need for a test for the co-integration test using the Johansen (1991) co-integration technique.

Table 2. Result of the adf unit-roots for stationarity

\begin{tabular}{lllllll}
\hline \multirow{2}{*}{ Variables } & At level & \multicolumn{2}{l}{ At first difference critical value } & \multicolumn{2}{c}{ Remarks } \\
& Statistics & Statistics & $1 \%$ & $5 \%$ & $10 \%$ & \\
\hline indu & -2.878 & -4.181 & -4.38 & -3.6 & -3.24 & $\mathrm{I}(1)$ \\
Agri & -1.136 & -3.032 & -2.583 & -1.746 & -1.337 & $\mathrm{I}(1)$ \\
\hline
\end{tabular}

Source: Own Computation

3.2.2. Co-integration test analytical result

As the Johansen co-integration test is the lag length sensitive, the optimal lag length was determined using LR, FPE, AIC, HQIC, and SBIC information criteria indicated in Table 3.

Table 3. Optimal lag selection result

\begin{tabular}{|l|l|l|l|l|l|l|l|l|}
\hline Lag & LL & LR & Df & P & PEP & AIC & HQIC & SBIC \\
\hline $\mathbf{0}$ & -1166.83 & & & & $4.7 \mathrm{e}+41$ & 101.638 & 101.662 & 101.736 \\
\hline $\mathbf{1}$ & -1087.24 & $159.19^{*}$ & 4 & 0.000 & $6.6 \mathrm{e}+38^{*}$ & 95.0641 & $95.1386^{*}$ & $95.3603^{*}$ \\
\hline $\mathbf{2}$ & -1085.86 & 2.7577 & 4 & 0.000 & $8.4 \mathrm{e}+38$ & 95.292 & 95.4162 & 95.7857 \\
\hline
\end{tabular}

Source: Own Computation

Based on all the information criteria the optimal lag length was determined to be one. After determining the 
lag length, the next procedure is determining co-integration if exist and the number of co-integration using trace and max eigenvalue statistics as indicated in Table 4 below.

Table 4. Co-integration test using trace and max statistics

\begin{tabular}{|l|l|l|l|l|l|l|}
\hline $\begin{array}{l}\text { Maximum } \\
\text { Rank }\end{array}$ & Parms & LL & Eigenvalue & Trace statistics & $5 \%$ critical value & $\begin{array}{l}1 \% \\
\text { value }\end{array}$ \\
\hline 0 & 6 & -1099.66 & & 27.6163 & 15.41 & 20.04 \\
\hline 1 & 9 & 1087.5365 & 0.65173 & $3.3561 * 1 * 5$ & 3.76 & 6.65 \\
\hline 2 & 10 & 1085.8584 & 0.13577 & & & \\
\hline
\end{tabular}

Source: Own Computation

Notice: The $* 1 * 5$ indicates that this estimator has selected the number of co-integrating at $1 \%$ and $5 \%$ critical value.

Table 4 above indicated the presence of (1) co-integrating equation for both trace statistics at $1 \%$ and $5 \%$ level of significance. This means co-integration exists at those ranks where the value of the trace statistic is less than the $1 \%$ and $5 \%$ critical value. Again, the eigenvalues all lie below 1 indicates the presence of co-integration. To confirm the result done, the maximum Eigenvalue test shown in the following Table 5.

Table 5. Maximum statistics co-integration test results

\begin{tabular}{|l|l|l|l|l|l|l|}
\hline $\begin{array}{l}\text { Maximum } \\
\text { Rank }\end{array}$ & Parameters & LL & Eigenvalue & Trace statistics & $5 \%$ critical value & $1 \%$ critical value \\
\hline 0 & 6 & -1099.66 & & 24.2602 & 14.07 & 18.63 \\
\hline 1 & 9 & 1087.5365 & 0.65173 & $3.3561 * 1 * 5$ & 3.76 & 6.65 \\
\hline 2 & 10 & 1085.85 & 0.13577 & & & \\
\hline
\end{tabular}

Source: Own Computation.

As can be seen from Table 5 above, accepted the null hypothesis that there was a (1) co-integrating equation for maximum statistics at $1 \%$ and $5 \%$ level of significance. This confirmed the existence of co-integration exists at those ranks where the value of the trace statistic is less than the $1 \%$ and $5 \%$ critical value. The presence of cointegration between industry and agriculture indicates that there is long term equilibrium or a long-run relationship between the two sectors in Ethiopia's economy.

\subsubsection{Error correction model analysis}

To examine a Vector Error Correction Model (VECM) which adjusts to both short-run changes in sectors, deviations the long impact agricultural sector on the industrial sector and vice versa using Johansen long run normalization restricted normalization equation and calculate the speed of adjustment of the model shock. Table 6 indicates the analysis of the short-run error correction model speed of adjustment.

Table 6 . The short-run shock from long-run equilibrium adjustment

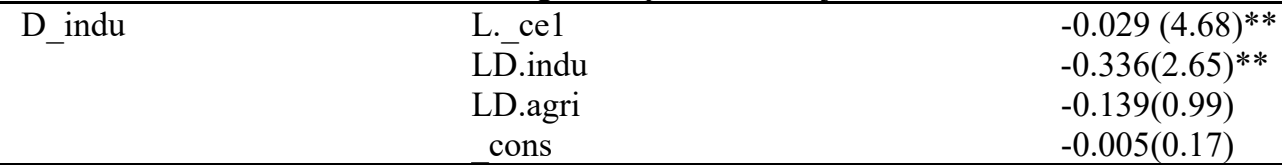

Source: Own Computation. Where L._ce1= lag length of co-integration equqtion1

As can be observed from the Table 9, short-run shock from long-run equilibrium adjustment in error correction mode analytical result indicates that the coefficient of the error correction term of industrial output (indu) co-integrating equation 1(L._ce1) is well behaved having possessed the expected negative sign, fractional and significant. The value of the error correction coefficient is -0.029 . This indicates that about $2.9 \%$ of the disequilibrium between the short-run and long-run relationships is corrected annually which is very small and it takes a long time to take full adjustment once shocked the long-run equilibrium. The R-squared value of 0.89 indicates that about $89.4 \%$ of the variability in industrial output in Ethiopia within the period under review was determined or influenced by agricultural sector output. also error correction equation 2 showed that agricultural sector output is sensitive to the shock in the short run. VECM Johansson's normalization analysis, which shows the long-run impact of the agricultural sector on the industrial sector, is indicated in the following Table 8 .

Table 7. The long-run impact of agriculture on the industry in Johansen normalized equation

\begin{tabular}{|l|l|l|l|}
\hline Beta & Coefficient & Standard & Probability $(<0.05)$ \\
\hline cel & & & \\
\hline Indu & 1 & 1.069 & \\
\hline Agri & 3.3878 & & 0.002 \\
\hline Constant & -93.69081 & & \\
\hline
\end{tabular}

Source: Own Computation

Johansen normalization equation analytical result in Table 7 above indicated that the long run agricultural has possessed and significant at $1 \%$ probability level other factors being constant. This implies that in the long run agricultural sector output has long run and positive impact in on the industrial sector output equation. It can be 
observed that when agricultural output increased by $1 \%$, other factors being industrial sector increase by $3.39 \%$. On the other hand, there is a need to test whether the industrial sector is has a long-run impact on the agricultural sector or not. The result of the Normalization equation showed in Table 8 below.

Table 8. The long-run impact of industry on agriculture in Johansen normalization co-integration

\begin{tabular}{|l|l|l|l|}
\hline Beta & Coefficient & Standard & $\mathrm{P}>\mathrm{Z}$ \\
\hline L._ce2 & & & \\
\hline agri & 1 & & \\
\hline indu & 0.295 & 1.54 & 0.124 \\
\hline Constant & -24.656 & & \\
\hline
\end{tabular}

Source: Own Computation

In the above Table 8, the analytical result of the error correction model Johansen normalization restricted equation (L._ce2) indicated that industrial output (indu) was not significant on agricultural output implies that the industrial sector has no long-run impact on the agricultural sector.

\subsubsection{Granger causality test result}

Since it was concluded from the previous test, i.e. the co-integration test that the two series are co-integrated, then there should be Granger causation at least in one direction. So at least one coefficient of the error term should enter equations and significantly and bear the correct sign, i.e. negative. As indicated by the Granger causality test, there was no causality between industrial and agricultural output; within the time under consideration in the Ethiopia economy.

Table 9. Granger short-run causality analysis result

\begin{tabular}{|l|l|l|l|l|}
\hline Equation & Exclude & Chi2 & Df & Prob chi2 \\
\hline Indu & Agri & 1.2062 & 2 & 0.547 \\
\hline Indu & All & 1.2062 & 2 & 0.547 \\
\hline Agri & Agri & 9.8034 & 2 & 0.007 \\
\hline Agri & All & 9.8034 & 2 & 0.007 \\
\hline
\end{tabular}

Source: own computation

The result of the pair-wise Granger Causality was used to test the above hypotheses as shown in Table 8 above: the null hypothesis agricultural doesn't Granger causes industry was accepted at least $10 \%$ significance level. On the other hand, the null hypothesis industry doesn't granger causes were rejected at the chi2 0.007 significance level. This means uni-* directional causality runs from industry to agriculture and not viscera.

\subsection{Post-Estimation Diagnostics}

In the study, different post-estimation diagnostic tests were performed to guarantee that the residuals from the model are Gaussian that the assumptions are not violated and the estimation results and inferences are trustworthy. 3.3.1. Lagrangian Multiplier (LM) autocorrelation test result

Table 12 analytical result shows whether there is serial correlation in the variables under consideration agriculture and industry outputs in ethiopia or not. the table shows that the null hypothesis assumes that there is no serial correlation between models variables is not rejected at probability $5 \%$ level significance. thus, the study could not find any evidence of the autocorrelation problem in the residuals.

Table 10. Lagrangian multiplier (LM) autocorrelation test result.

\begin{tabular}{|l|l|l|l|}
\hline Lag length & Chi2 & Df & Prob $>$ chi2 \\
\hline 1 & 8.25 & 4 & 0.08 \\
\hline 2 & 1.47 & 4 & 0.83 \\
\hline
\end{tabular}

Ho: No autocorrelation at lag one

Source: Own Computation

\subsubsection{Residual vector normality test}

Normality was checked mainly by using the Jarque-Bera test. The result (in Table 11 ) shows the null hypothesis that the residual vector of the model is found to be jointly normal is not rejected at a $10 \%$ significant probability level which means the residual is normally distributed.

Table 11.Residuals Vector Jarque-Bera Normality Test

\begin{tabular}{|l|l|l|l|}
\hline Equation & Chi2 & Df & Prob $>$ chi2 \\
\hline Indu & 0.537 & 2 & 0.76454 \\
\hline Agri & 0.671 & 2 & 0.71483 \\
\hline ALL & 1.208 & 4 & 0.87672 \\
\hline
\end{tabular}

Source: Own Computation

\section{CONCLUSION AND RECOMMENDATION}

The econometric analytical result indicated that agricultural and industrial sectors' output series move together. 
The result of the ADF stationarity unit root test indicates that both stationary of difference one and the Johnson co-integration tests of maximum likelihood ratio trace and max eigenvalue statistics indicate that the variables are co-integrated of order one implies the two sectors output series in Ethiopian have long-run equilibrium relationship.

Johansen normalized restricted equation error correction model indicated that a $1 \%$ increase in agricultural output leads to $3.39 \%$ increase in industrial sector output being other factors held constant. This means that agricultural sector output has a long run, strong and positive impact on the industrial sector but no vice versa. This may be because the industrial sector in Ethiopia is in the infant stage.

The industrial short-run shock speed of adjustment from the long-run equilibrium of error correction model coefficient was negative, fraction and significant implies that the industrial sector is shocking responsive despite its response is very small only $2.9 \%$ adjustment next year and takes a long time for full adjustment. The null hypothesis of agriculture doesn't Granger causes industry was not rejected at $10 \%$ significance implies in the short run agriculture doesn't cause industry and the null hypothesis industry sector don't granger causes agriculture was rejected at $1 \%$ significance level implies that industry has a short-run impact on agriculture. This means there is a short run, unidirectional causality running from the industry sector to the agriculture sector. Therefore, it can be concluded that agriculture has no short-run impact on the industry, and the industry has a strong short-run impact on agriculture. On the other hand, Johannes's normalization equation indicates that agriculture has a strong and positive long-run impact on the industry and not vice versa. Implies agricultural sector output has long run on industrial sector series output. In addition, the short-run causality test indicated that industrial out series has shortrun causality on agriculture.

Therefore, policymakers should reconsider the ADLI policy strategy as the right policy and should ensure balanced growth of both the Agricultural sector and industrial sector ensuring both forward and backward linkages between the two sectors for the overall development of the Ethiopian economy.

\section{REFERENCES}

Alston, J.M. and Pardey, P.G. 2014. Agriculture in the Global Economy. Journal of Economic Perspectives, Vol. 28 (1), pp. $121-146$.

Dia Xinsho .2010. Economic Importance of Agriculture for Sustainable Development and Poverty Reduction: The Case Study of Ethiopia. Global Forum on Agriculture 29-30 November.

Dickey, D., and Fuller, W. 1979. Distribution of the Estimators for autoregressive time series with a unit root. Journal of the American Statistical Association, 74(3):427-431.

Dickey, D., and W. Fuller. 1976. Likelihood ratio test statistics for autoregressive time series with a unit root. Econometrical 49: 1057-1072.

Dickey, D., and W. Fuller. 1979. Distribution of the Estimators for Autoregressive Time Series with a Unit Root. Journal of American Statistics Association, 74(366): 427- 31.

Godfrey LG .1978. Testing for Higher-Order Serial Correlation in Regression Equations when the Regressors Include Lagged Dependent Variables." Econometric, 46, 1303.

Granger, C.W.J. 1969. Investigating causal relations by econometric models: cross-spectral methods', Econometrical, 37, 424-38.

Greene, W. H. 2006. Econometric Analysis, 5th Edition Greene, Academic Internet Publishers, 2006.

Gujarati, D. 2004. Basic Econometrics. Fourth Edition. McGraw-Hill Companies.

Hye, Q.M.A.2009. Agriculture on the road to industrialization and sustainable economic growth: An empirical investigation for Pakistan. International Journal of Agricultural Economics and Rural Development: 2: 1-6.

International Monetary Fund (IMF). Ethiopian Economic Review, 2016. The story behind the number. https://www2.deloitte.com.

Johansen, S., and Juselius, K. 1990. Maximum Likelihood Estimation and Inference on Cointegration - with Application to the Demand for Money, Oxford Bulletin of Economics and Statistics, 52, 169-210.

Kwiatkowski, D., Phillips, P. C. B., Schmidt, P., and Shin, Y. 1992. Testing the null hypothesis of stationarity against the alternative of a unit root: How sure are we that economic time series have a unit root?" Journal of Econometrics, Vol.54.

Phillips, P. C. B., Schmidt, P., and Shin, Y. 1992. Testing the null hypothesis of stationarity against the alternative of a unit root: How sure are we that economic time series have a unit root?" Journal of Econometrics, Vol.54, October-December (1-3), pp.

Phillips, P.C., and P. Perron. 1988. Testing for a unit root in time series regression. Biometrika, 75(2): 335-346.

Rural development policy and Strategies, 2003. Government of the federal democratic republic of Ethiopia, Addis Ababa. Ethiopia.

XINsho.2010. Policies for Agricultural Development, Poverty Reduction, and Food Security OECD Headquarters, Paris.

Koo, W. W., \& Jianqiang L., (1997). The Relationship between the Agricultural and Industrial sectors in Chinese Economic Development. Agricultural Economics Report No. 368. 